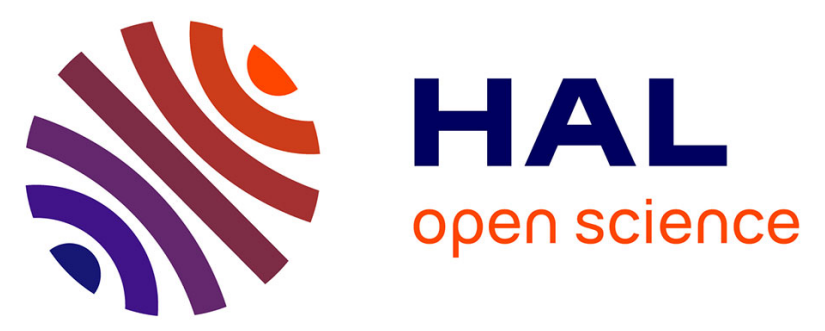

\title{
MASSAGE AND MOBILIZATION OF THE FEET AND ANKLES IN ELDERLY ADULTS: EFFECT ON CLINICAL BALANCE PERFORMANCE
}

\author{
Jacques Vaillant, Audrey Rouland, Pascale Martigné, Renaud Braujou,
} Michael J. Nissen, Jean-Louis Caillat-Miousse, Nicolas Vuillerme, Vincent Nougier, Robert Juvin

\section{To cite this version:}

Jacques Vaillant, Audrey Rouland, Pascale Martigné, Renaud Braujou, Michael J. Nissen, et al.. MASSAGE AND MOBILIZATION OF THE FEET AND ANKLES IN ELDERLY ADULTS: EFFECT ON CLINICAL BALANCE PERFORMANCE. Manual Therapy, 2009, 14 (6), pp.661-664. 10.1016/j.math.2009.03.004 . hal-00391434

\section{HAL Id: hal-00391434 https://hal.science/hal-00391434}

Submitted on 4 Jun 2009

HAL is a multi-disciplinary open access archive for the deposit and dissemination of scientific research documents, whether they are published or not. The documents may come from teaching and research institutions in France or abroad, or from public or private research centers.
L'archive ouverte pluridisciplinaire HAL, est destinée au dépôt et à la diffusion de documents scientifiques de niveau recherche, publiés ou non, émanant des établissements d'enseignement et de recherche français ou étrangers, des laboratoires publics ou privés. 


\section{MASSAGE AND MOBILIZATION OF THE FEET AND ANKLES \\ IN ELDERLY ADULTS: EFFECT ON CLINICAL BALANCE PERFORMANCE}

Jacques Vaillant ${ }^{125^{*}}$, Audrey Rouland ${ }^{2}$, Pascale Martigné2 ${ }^{2}$ Renaud Braujou ${ }^{23}$, Michael J.

Nissen $^{4}$, Jean-Louis Caillat-Miousse ${ }^{2}$, Nicolas Vuillerme ${ }^{1}$, Vincent Nougier ${ }^{1}$, Robert Juvin ${ }^{5}$

${ }^{1}$ Laboratoire Santé Plasticité Motricité, Université Joseph Fourier-Grenoble 1, Grenoble, France.

${ }^{2}$ Ecole de Kinésithérapie du Centre Hospitalier Universitaire de Grenoble, France.

${ }^{3}$ Hôpital de Saint-Laurent-du-Pont, Saint-Laurent-du-Pont, France.

${ }^{4}$ Service de Rhumatologie du Centre Hospitalier Universitaire de Genève, Suisse.

${ }^{5}$ Service de Rhumatologie du Centre Hospitalier Universitaire de Grenoble, France.

\section{*Correspondence:}

Jacques VAILLANT

Ecole de kinésithérapie du Centre Hospitalier Universitaire de Grenoble BP 217

F 38041 Grenoble cedex 09

France.

Tel: +33476765256

Fax: +33476765918

E-mail: JVaillant@chu-grenoble.fr 


\section{ABSTRACT}

The aim of this study was to evaluate the effects of a session of plantar massage and joint mobilization of the feet and ankles on clinical balance performance in elderly people. A randomized, placebo-controlled, cross-over trial was used to examine the immediate effects of manual massage and mobilization of the feet and ankles. Twenty-eight subjects, aged from 65 to 95 years $(78.8 \pm 8.5$ years - mean $\pm \mathrm{SD})$ were recruited from community nursing homes. Main outcome measures were the performances in three tests: One Leg Balance (OLB) test, Timed Up and Go (TUG) test and Lateral Reach (LR) test. Results demonstrated a significant improvement after massage and mobilization compared with placebo for the OLB test $(1.1 \pm 1.7$ seconds versus $0.4 \pm 1.2$ seconds, $\mathrm{p}<0.01)$ and the TUG test $(0.9 \pm 2.6$ seconds versus $0.2 \pm 1.2$ seconds, $\mathrm{p}<0.05)$. Conversely, performances in the LR test did not improve significantly. These results emphasise the positive impact of a single session of manual therapy applied to the feet and ankles on balance in elderly subjects.

Key words: Balance; Elderly; Massage; Mobilization; Physical therapy; Ankle; Foot. 


\section{Introduction:}

The cause of falls in the elderly is multifactorial (Tinetti, 2003). Amongst the many factors described, the fact that the aging process results in reduced joint flexibility and reduced afferent sensory information is well established.

All joints show a significant reduction in range of motion (ROM) with age. Ankle dorsiflexion (knee extended) shows the greatest age-related decline (James et al., 1989). Decrease in dorsiflexion ROM is associated with normal aging in both men and women (Gadjosik et al., 1999; Vandervoort et al., 1992). Fallers show a reduced ankle ROM (Kemoun et al., 2002). Despite the atrophy of the ankle musculature which occurs with aging, passive resistive torque of stretched connective tissue shows an increasing trend in older subjects (Vandervoort et al., 1992).

Adequate ROM of the ankle and MTP joints is an important prerequisite to enable balance and locomotion which are essential daily activities (Lung et al.1996). Walker et al. (1984) found an age-related decrease in flexion of the first metatarsophalangeal (MTP) joint. Moreover, Mecagni et al. (2000) showed a correlation between ankle ROM and balance in community-dwelling elderly women.

In addition to the musculoskeletal aspects, control of balance requires coordinated activity of the neuromuscular system. Accurate sensory inputs are necessary to organize motor programs and to generate effective motor output responses (Vandervoort, 1999). Sensations from the bottom of the feet play an important role during dynamic postural responses (Perry et al., 2000; Perry, 2006). Therefore, two important sources of information, cutaneous input from the feet and joint input from the feet and ankles, could be manipulated. In previous studies, the effects of (1) mechanical stimulation of the feet (Bernard-Demanze et al., 2004) and (2) massage and manipulation of the feet (Vaillant et al., 2008) on postural 
control during quiet standing have been shown. However, effects on functional balance performances were unknown.

Few functional balance tests have been validated, although they are commonly used. The One Leg Balance test (OLB) is one of the most common tests used to measure balance in older people (Jarnlo and Nordell, 2003) and is a simple predictive test for injury-related falls (Vellas et al., 1997). The Timed Up and Go (TUG) test is a convenient and reliable test for estimating physical mobility (Podsiadlo and Richardson, 1991). The importance of mediolateral postural control has been demonstrated to be a significant factor in the identification of elderly fallers (Brauer et al., 1999; Lord et al., 1999; Maki et al., 1994; Maki and McIlroy, 1998). The Lateral Reach (LR) test was found to be a valid indicator of lateral stability limits (Brauer et al., 1999).

The aims of this study were firstly to compare the impact of massage and mobilization of the feet and ankles versus placebo on functional balance performance, and secondly to improve the understanding of the role played by distal lower limb inputs in balance control during functional activities.

\section{Methods:}

\section{Population}

Healthy volunteers were recruited from three community nursing homes, with help from managers. The criteria for inclusion were: age over 65 years and the ability to walk 10 meters. Subjects were excluded if they had severe cognitive impairment, rapidly progressive or terminal illness, acute illness or unstable chronic illness, myocardial infarction or a fracture of the lower limb, within the six months prior to inclusion.

Twenty eight subjects with a mean age of 78.8 years (SD=8.5 years, range 65 to 95 years, $15 / 28$ women) completed written consent to the study as required by the Helsinki 
declaration (1964) and the local Ethics Committee. One subject dropped out of the study because of lack of interest. Each of the remaining 27 subjects participated in two experimental sessions. Fourteen subjects received the massage and mobilization in the first experimental session and the placebo condition during the second session, while the remaining 13 subjects received the same interventions in the reverse order.

\section{Experimental Design}

For this cross-over study, two sessions were organized: one involved massage and mobilization and the other, application of placebo. In order to avoid carry-over effects, at least one week separated the two sessions which were performed in random order. The measurements were obtained immediately before and after each of these protocols.

\section{Measurement procedure:}

The functional tests, all performed in the following order, included the OLB test (Vellas et al., 1997), the TUG test (Podsiadlo and Richardson, 1991) and the LR test (Brauer et al., 1999).

The OLB and TUG tests were timed with a digital stopwatch by an assessor blinded to the randomization protocol.

Three trials were performed and the mean time was calculated. For the LR test, three trials on each side were carried out and the mean distance was calculated.

Functional test description

One leg balance test:

The subjects stood on one leg with the other slightly flexed, first the right and then the left, for as long as possible without shoes, looking at a target. Three trials on each leg were allowed. During the test, the subject was not allowed to move the foot from the floor (Vellas et al., 1997). 
Timed Up and Go test:

A high straight-backed office chair with arm rests was placed 3 meters from a wall. Subjects sat comfortably in the chair and were asked to rise and stand still momentarily, walk towards the wall, turn without touching the wall, walk back to the chair, turn around and then sit down again. The score given was the time in seconds required to complete the test (Podsiadlo and Richardson, 1991).

Lateral Reach test:

The subjects stood with their back against (but not in contact with) a wall. The feet were placed in a standardized position with $10 \mathrm{~cm}$ between the most medial aspects of the heels and at an outwards angle of 30 degrees. To ensure accurate recording of the initial hand position, subjects stood for 10 seconds with both arms abducted to 90 degrees and maintained equal weight bearing. Subjects were given standardized instructions and encouragements to reach directly sidewards as far as possible without overbalancing, taking a step or touching the wall. The contralateral arm remained by their side during the reach. Both feet had to remain fully in contact with the support surface throughout the task, no knee flexion was permitted and no trunk rotation or flexion was tolerated (Brauer et al., 1999).

\section{Therapeutic protocol}

The massage and mobilization protocol included a therapeutic manipulation of the feet and ankles. This intervention, widely used by physical therapists (Dufour, 1996) was designed to target the somatosensory system of the feet and ankles. Given that the somatosensory system includes multiple receptors that provide information about pressure distribution (cutaneous), muscle tension (Golgi tendon organs), joint angle changes (joint receptors) and muscle length changes (spindles), the intervention involved manual massage of the feet and mobilization of the feet and ankle joints. 
Intervention methods were standardized. Half of the allocated time was for massage and the other half for joint mobilisation. The aim of the massage was to enhance local blood circulation and to stimulate cutaneous receptors. The massage technique (Clay and Pounds, 2006) involved the application of friction, static and glide pressure focus on the sole of the foot. Multidirectional, systematic tractions on the sole of the foot were performed particularly in the heel region and over the metatarsal heads.

Mobilization involved dorsiflexion and plantar flexion of the talocrural joints, eversion and inversion of the subtalar joints, anteroposterior glide, torsion, flexion and extension of the midtarsal joints, anteroposterior glide and rotation of the tarsometatarsal joints, anteroposterior glide of the intermetatarsal joints, and plantar flexion and extension of the MTP and interphalangeal joints. Each manipulation was performed three times per foot. Manual massage and joint mobilization were applied to the feet and ankles for a total of 20 minutes.

\section{Placebo protocol}

The placebo protocol consisted of the application of three demagnetized magnets in the region of the fifth metatarsals for 20 minutes.

\section{Statistical analysis:}

The data was analysed with "R" statistical software (Version 2.4.0) and as it was not normally distributed (Shapiro-Wilk normality test), the Wilcoxon rank test was used to test statistical differences between sessions. Test-retest reliability was performed on preintervention data by using Intraclass Correlation Coefficients (ICCs). In addition, the Standard Error of Measurement (SEM) was determined for each of the continuous variables according to the following equation: SEM=SD x $\sqrt{ }(1-$ ICC $)$ and the Smallest Detectable Difference (SDD) was calculated as SDD $=\mathrm{SEM} \times 1.96$ ( $\mathrm{z}$ score for $95 \%$ confidence $) \times \sqrt{ } 2$. A two-sided $\mathrm{p}$ value less than or equal to 0.05 was considered to indicate statistical significance. 


\section{Results:}

Reliability of the tests. The results demonstrated a good reliability between the three tests. Despite of the frailty of many of the patients, the ICCs of the observations for the same observer between pre-tests were: 0.98 for the OLB test, 0.98 for TUG test and 0.92 for LR test. 95\% CI, SEM and SDD were also calculated (table 1).

Treatment $\boldsymbol{v s}$. placebo (Table 2). After the massage and mobilization protocol (MMP) (Figures 1 and 2), the improvement of performance in the OLB test and the TUG test was greater with respect to the placebo protocol (PP). Mean $( \pm \mathrm{SD})$ changes in the OLB test were $1.1( \pm 1.7)$ seconds for MMP and $0.4( \pm 1.2)$ seconds for PP $(\mathrm{p}<0.01)$. Mean $( \pm S D)$ changes in the TUG test were $0.9( \pm 2.6)$ seconds for MMP and $0.2( \pm 1.2)$ seconds for PP $(\mathrm{p}<0.05)$. Conversely, the improvement in the LR test was not significantly different between $\operatorname{MMP}(1.3 \pm 2.3 \mathrm{~cm})$ and $\mathrm{PP}(0.8 \pm 1.3 \mathrm{~cm})$.

\section{Insert Figure 1 and 2 about here}

\section{Discussion:}

Results showed a statistically significant improvement in performance for both the OLB test and the TUG test, whereas the LR test did not improve significantly.

Several other studies have reported findings of a similar nature. André-Deshays and Revel (1988) demonstrated the sensory role of the plantar sole, particularly with regards to sense of movement in the mediolateral direction. Kavounoudias et al. (2001) established that the anterior region of the sole (heads of the first metatarsal and of the fifth metatarsal) demonstrate high discrimination capacities. Perry et al. (2000) reported the importance of cutaneous receptors from the plantar sole in controlling specific aspects of rapid 
compensatory stepping reactions caused by postural perturbations. Since then, Perry et al. (2006), Bernard-Demanze et al. (2004) and Vaillant et al. (2008) have all demonstrated that the quality of somatosensory information plays a major role in postural control. Improvement of somatosensory information could potentially explain the benefit observed in our study.

On the other hand, the improvement may also be related to mechanical effects. The importance of ROM of the feet and ankle joints with regards to balance and locomotion performance is also known. Mecagni et al. (2000) showed a correlation between ankle ROM and the functional reach test. In our study, changes of joint ROM were not measured. This hypothesis needs to be explored further in future studies.

Even though the tests demonstrated good reliability in our prestudy, the results have to be put into perspective, in that the improvements after the massage and mobilization protocol were less than or equal to the SEM and SDD (Tables $1 \& 2$ ). Moreover, the 1.1 and 0.9 second improvements for the OLB and TUG tests respectively observed in our study, were similar to the minimal detectable change usually considered to be between 1 and 2 seconds (Piva et al., 2004; Lim et al., 2005). Nevertheless, the use of demagnetized magnets as placebo, as previously described by Martel et al. (2002), would allow us to consider that these results are robust. In addition, the crossover with the placebo session allowed us to neutralize the warm-up and apprenticeship effects. With regards to the LR test, the cross-over with the placebo session enabled us to neutralize the improvement in performance linked to the repetition of the movement (Brauer et al, 1999). This learning phenomenon could explain the $0.8 \mathrm{~cm}$ improvement in the placebo group, which was not statically different from the $1.3 \mathrm{~cm}$ improvement in the massage and mobilization protocol.

In the context of a progressively ageing population and increasing falls, these results after only a single 20 minute intervention are very promising. There were however several limitations to the study protocol. Firstly, the brief period during which the subjects were 
treated is unusual. It is generally acknowledged that a standard protocol of therapeutic intervention consists of sessions of at least 20 minutes that are repeated several times per week over a period of approximately 10 weeks (American Geriatrics Society et al., 2001). Secondly, in the present experiment, the effect of the therapeutic intervention on clinical performance was assessed immediately after the therapeutic manipulation. It is therefore impossible to judge the potential durability of the reported improvement. Moreover, the impact of manipulative techniques and joint mobilization versus massage of the plantar sole is unknown. Further research is required to clarify these outstanding questions.

\section{References}

American Geriatrics Society, British Geriatrics Society, and American Academy of Orthopaedic Surgeons Panel on Falls Prevention. Guideline for the Prevention of Falls in Older Persons. Journal of American Geriatrics Society 2001;49:664-72.

André-Deshays C, Revel M. Evaluation de la sensibilité kinesthésique de la cheville. Application à la rééducation. Annales de Réadaptation et Médecine Physique 1988;31:367-76.

Bernard-Demanze L, Burdet C, Berger L, Rougier P. Recalibration of somesthetic plantar information in the control of undisturbed upright stance maintenance. Journal of Integrative Neurosciences 2004;3:433-51.

Brauer S, Burns Y, Galley P. Lateral reach: a clinical measure of medio-lateral postural stability. Physiotherapy Research International 1999; 2:81-8.

Clay JH, Pounds DM. Basic clinical massage therapy: integrating anatomy and treatment. NewYork: Lippincott Williams and Wilkins, 2006.

Dufour M. Massages. Encyclopédie Médico-Chirurgicale, Kinésithérapie-Médecine physiqueRéadaptation. Paris: Elsevier, 1996. 
Gadjosik RL, Vander Linden DW, Williams AK. Influence of age on length and passive elastic stiffness characteristics of the calf muscle-tendon unit of women. Physical Therapy $1999 ; 79: 827-38$.

James B, Parker AW. Active and passive mobility of lower limb joints in elderly men and women. American Journal of Physical Medicine 1989;68(4):162-7.

Jarnlo GB, Nordell E. Reliability of the modified figure of eight - a balance performance test for elderly women. Physiotherapy Theory Practice 2003;19:35-43.

Kavounoudias A, Roll R, Roll JP. Foot sole and ankle muscle inputs contribute jointly to human erect posture regulation. Journal of Physiology 2001;532:869-78.

Kemoun G, Thoumie P, Boisson D, Guieu JD. Ankle dorsiflexion delay can predict falls in elderly. Journal of Rehabilitation Medicine. 2002; 34: 278-83.

Lim L, van Wegen E, de Goede C, et al. Measuring gait and gait-related activities in Parkinson's patients' own home environment: a reliability, responsiveness, and feasibility study. Parkinsonism Relat Disord. 2005;11:19-24.

Lord SR, Rogers MW, Howland A, Fitzpatrick R. Lateral stability, sensorimotor function and falls in older people. Journal of American Geriatrics Society 1999;47(9):1077-81.

Lung MW, Hartsell HD, Vandervoort AA. Effects of aging on joint stiffness: Implications for exercise. Physiotherapy Canada 1996; 48(2):96-106.

Maki BE, Holiday PJ, Topper AK. A prospective study of postural balance and risk of falling in an ambulatory and independent elderly population. Journal of Gerontology 1994;49:M7284.

Maki BE, McIlroy WE. Control of compensatory stepping reactions: age-related impairment and potential for remedial intervention. Physiotherapy Theory and Practice 1998;15:69-90. 
Martel GF, Andrews SC, Roseboom CG. Comparison of static and placebo magnets on resting forearm blood flow in young, healthy men. J Orthop Sports Phys Ther. 2002;32(10):51824.

Mecagni C, Smith JP, Roberts KE, O’Sullivan SB. Balance and ankle range of motion in community-dwelling women aged 64 to 87 years: A correlational study. Physical Therapy 2000; 80:1004-11.

Perry SD, McIlroy WE, Maki BE. The role of plantar cutaneous mechanoreceptors in the control of compensatory stepping reactions evoked by unpredictable, multi-directional perturbation. Brain Research 2000;877:401-6.

Perry SD. Evaluation of age-related plantar-surface insensitivity and onset age of advanced insensitivity in older adults using vibratory and touch sensation tests. Neuroscience Letters 2006;392:62-7.

Piva SR, Fitzgerald GK, Irrgang JJ, Bouzubar F, Starz TW. Get up and go test in patients with knee osteoarthritis. Archives of Physical Medicine and Rehabilitation 2004;5(2):284-9.

Podsiadlo D, Richardson S. The timed «Up and Go »: A test of basic functional mobility for frail elderly persons. Journal of American Geriatrics Society 1991;39:142-8.

Tinetti ME. Preventing falls in elderly persons. New England Journal of Medicine 2003;348:42-9.

Vaillant J, Vuillerme N, Janvy A, Braujou R, Louis F, Juvin R, Nougier N. Effect of manipulation of the feet and ankles on postural control in elderly adults. Brain Research Bulletin 2008;75:18-22

Vandervoort AA, Chesworth BM, Cunningham DA, Paterson DA, Rechnitzer PA, Koval JJ. Age and sex effects on mobility of the human ankle. Journal of Gerontology 1992;47:M17-21.

Vandervoort AA. Ankle mobility and postural stability. Physiotherapy Theory Practice 1999;15:91-103. 
Vaillant J et al. Manual Therapy (2009), doi:10.1016/j.math.2009.03.004

Vellas BJ, Wayne SJ, Romero L, Baumgartner RN, Rubenstein LZ, Garry PJ. One-leg balance is an important predictor of injurious falls in older persons. Journal of American Geriatrics Society $1997 ; 45: 735-8$.

Walker JM, Sue D, Miles-Elkousy N, Ford G, Trevelyan H. Active mobility of the extremities in older subjects. Physical Therapy 1984;64:919-23. 
Table 1: Reliability of pre-test

\begin{tabular}{lcccc}
\hline & ICC & $95 \%$ CI & SEM & SDD \\
\hline OLB (sec) & 0.98 & $0.73-0.99$ & 0.98 & 2.73 \\
TUG (sec) & 0.98 & $0.96-0.99$ & 0.99 & 2.74 \\
LR $(\mathrm{cm})$ & 0.92 & $0.88-0.98$ & 0.96 & 2.65 \\
\hline
\end{tabular}

Table 2: Pre-tests, Post-tests and improvements $(\Delta)$ during massage and mobilization protocol and placebo protocol. $(\mathrm{n}=27)$

\begin{tabular}{lcccccc}
\hline & \multicolumn{2}{c}{ Massage mobilization protocol } & \multicolumn{3}{c}{ Placebo protocol } \\
& Pre-test & Post-test & $\Delta$ & Pre-test & Post-test & $\Delta$ \\
\hline $\begin{array}{l}\text { OLB }^{\mathrm{a}} \\
(\mathrm{sec})\end{array}$ & $5.17 \pm 7.97$ & $6.22 \pm 7.73$ & $1.05 \pm 1.65$ & $5.36 \pm 8.01$ & $5.77 \pm 7.94$ & $0,41 \pm 1,19$ \\
$\mathrm{TUG}^{\mathrm{a}}$ & $21.55 \pm 10.88$ & $20.63 \pm 11.76$ & $0.92 \pm 2.63$ & $20.82 \pm 9.92$ & $20.65 \pm 9.91$ & $0.17 \pm 1.24$ \\
$(\mathrm{sec})$ & & & & & & \\
$\mathrm{LR}^{\mathrm{a}}(\mathrm{cm})$ & $11.59 \pm 5.90$ & $12.86 \pm 6.59$ & $1.28 \pm 2.27$ & $11.47 \pm 5.82$ & $12.30 \pm 5.77$ & $0.83 \pm 1.25$ \\
\hline${ }^{\mathrm{a}}$ Mean (SD) & & & & & &
\end{tabular}




\section{Figure captions}

Figure 1. Changes (in seconds) in the Timed Up and Go test and the One leg balance test between the value obtained after the treatment protocol vs. placebo and the baseline value.

Figure 2. Changes (in $\mathrm{cm}$ ) in the Lateral Reach test between the value obtained after the treatment protocol $v s$. placebo and the baseline value. 
Figure 1.

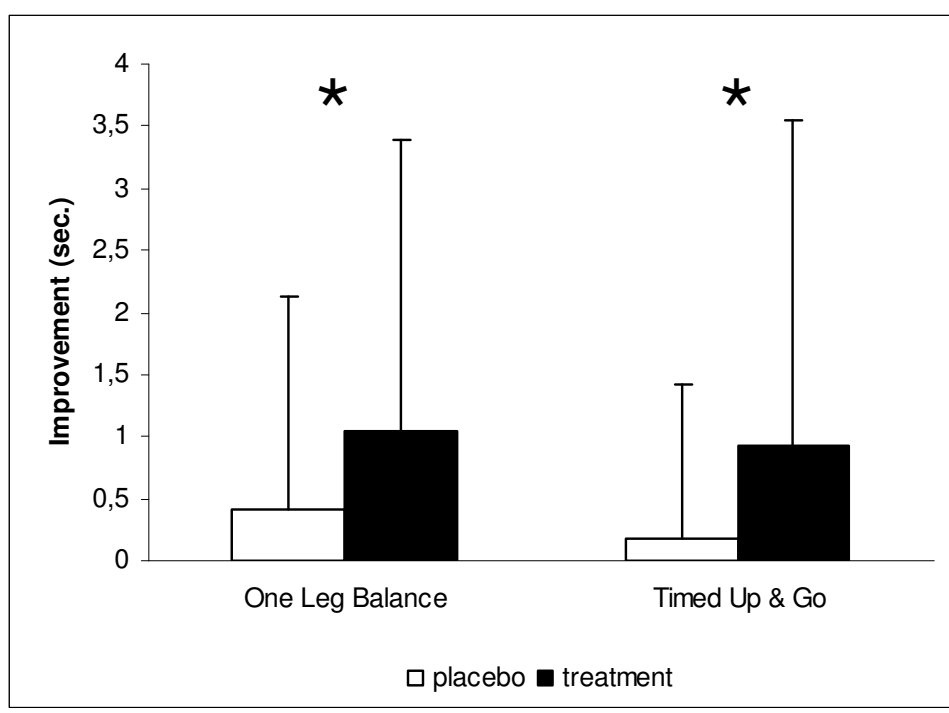

$\star \mathrm{p}$ value $<0.05$

Figure 2.

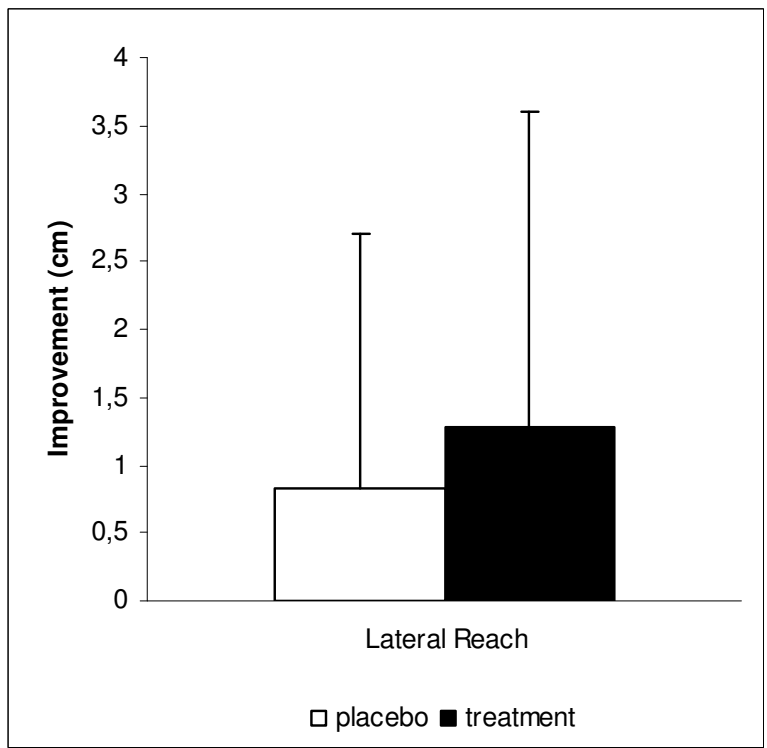

